\title{
FABRICATION AND TESTING OF A SEMI-MANUALLY OPERATED FISH SCALE REMOVER
}

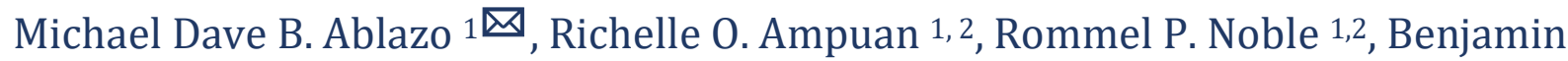
D. Varela ${ }^{1,2}$

${ }^{1}$ Department of Agricultural Engineering, College of Engineering, University of Eastern Philippines, Catarman, Northern Samar, Philippines

2 University Research and Development Services, University of Eastern Philippines

Catarman, Northern Samar, Philippines

DOI: https://doi.org/10.29121/IJOEST.v4.i5.2020.119

Article Type: Research Article

Article Citation: Michael Dave B. Ablazo, Richelle 0. Ampuan, Rommel P. Noble, and Benjamin D. Varela. (2020). FABRICATION AND TESTING OF A SEMI-MANUALLY OPERATED FISH SCALE REMOVER. International Journal of Engineering Science Technologies, 4(5), 89-97. https://doi.org/10.29121/IJOEST.v 4.i5.2020.119

Received Date: 2 October 2020

Accepted Date: 22 October 2020

\section{Keywords:}

Fish Scale Remover

Scaling Capacity

Scaling Efficiency

\section{ABSTRACT}

Commercial fish scale removers are very expensive. This study was conducted in order to fabricate and test the performance of a low cost, stand-alone semi-manually operated fish scale remover. The randomized complete block design (RCBD) quasi-experiment was used to test the capacity and efficiency of the semi-manually operated fish scale remover. Three (3) different kinds of fish in Northern Samar (Bangus, Sagision and Kirawan) with three (3) different sizes of scales (Large, Medium and Small) were used in the testing of the fabricated fish scale remover at three (3) different speeds of the scaling drum (High, Medium and Low). The results revealed that the higher the speed of the scaling drum, the higher is the scaling capacity of the manually-operated fish scale remover. Likewise, the bigger the scales of fish being descaled, the higher is the scaling capacity of the manually-operated fish scale remover. The average scaling capacity of the fish scale remover is higher than the average scaling capacity of an experienced fish vendors for kirawan and sagision but is lower than that of the experienced fish vendors for bangus. On the other hand, the average scaling efficiencies of the machine for all the fish used in testing the machine were highest at medium speed setting of the scaling drum. The cost and return analysis on the operation of the semi-manually operated fish scale remover revealed that it will have an annual net income of $\mathrm{P}$ $48,724.37$, a payback period of 50 days, and a rate of return of 3.82. The actual cost of constructing the semi-manually operated fish scale remover is $\mathbf{P} 12,756.00$.

\section{INTRODUCTION}

Technological innovation is very advance nowadays. For this reason, man is determined to conduct more beneficial projects and upgrade devices/equipment for special purposes. Our local communities are composed of different groups of people with different needs and concerns. Community folks, like fishermen and fish vendors need improved equipment to sustain post-fishing operations just like fish scaling wherein fish scale is removed from the fish prior to cooking (Byrd, 1951).

(C) 2020 The Author(s). This is an open access article distributed under the terms of the Creative Commons Attribution License, which permits unrestricted use, distribution, and reproduction in any medium, provided the original author and source are credited. 
In the Philippines, the common practice of removing fish scales is done by moving the dull side of a knife, spoon, fork, or wood with spike nails against the fish in a direction opposite to the extending scales (Dela Cruz, 1983). This procedure, however, is difficult, time consuming, and very messy since the removed scales is snapping off in a variety of directions. The tool must be repeatedly moved over the same area of the fish in order to ensure that all scales are removed and so there is that tendency to destroy the skin of the fish.

There are already many fish scale removers commercially available in the market and advertised in the internet. Fish scalers are manufactured in the US and China. Particularly, there is a model of fish scaler in the US like (a) the DS-800 which has a power requirement of $1.1 \mathrm{~kW} / 380 \mathrm{~V}$ and a capacity of $800 \mathrm{~kg} / \mathrm{hr}$; (b) the DS-1500 requiring a power of $3 \mathrm{~kW} / 380 \mathrm{v}$ and has a capacity of 1,500 kg/hr; (c) the DS- 5000 which has a power of 5.5 $\mathrm{kW} / 380 \mathrm{v}$ and a capacity of 5,000 kg/hr; (d) the cordless, rechargeable fish scaler; and (e) a hand held, electrically operated fish scaler which has been already patented by William Tietz, Leonard Fisher, Floyd Saizon and the Bay State Fishing Company (Clucas and Sutliffi, 1981). However, the stand alone fish scale removers are very expensive, with prices ranging from US\$1,000 - 1,200 and are not readily available in the Philippines.

Tripodi et al. (1974) stated that an electric fish scaler comprising of a motor, a pair of oppositely rotating eccentric cams in a driven connection with said motor, a pair of fulcrum mounted arms engaging said cams being actuated in a scissor like manner separately and sequentially there by and having, respectively, a terminal knife edge and shoe member at the free ends provide a fish scaler of relatively economical manufacture which is capable of convenient handling and efficient performance. But this is not available in the Philippine market. In this work, a locally manufactured/developed fish scale remover is deem necessary to address this problem, and, hence, this research study on a semi-manually operated fish scale remover was proposed.

\section{MATERIALS AND METHODS}

The Randomized Complete Block Design (RCBD) was used to evaluate the capacity and efficiency of the semimanually operated fish scale remover. Three (3) different kinds of fish (Bangus, Sagision and Kirawan) with different sizes of scales (Large, Medium and Small) were scaled off at varying speed of the scaling drum (High, Medium and Low). Therefore, the treatment combinations are presented in Table 1.

Table 1: The treatment combinations employed in this study.

\begin{tabular}{|c|c|c|}
\hline Kind of Fish & Scaling speed & Treatment Combination \\
\hline \multirow{3}{*}{ Bangus } & Low speed & BLS \\
\cline { 2 - 3 } & Medium Speed & BMS \\
\cline { 2 - 3 } & High speed & BHS \\
\hline \multirow{3}{*}{ Sagision } & Low speed & SLS \\
\cline { 2 - 3 } & Medium speed & SMS \\
\cline { 2 - 3 } & High speed & SHS \\
\hline \multirow{3}{*}{ Kirawan } & Low speed & KLS \\
\cline { 2 - 3 } & Medium speed & KMS \\
\cline { 2 - 3 } & High speed & KHS \\
\hline
\end{tabular}

This study observed the following scientific procedure in achieving its objectives:

\subsection{DESIGN AND FABRICATION OF THE SCALE REMOVER}

Based on the previous designs of fish scale removers seen in the internet, the researchers created a design applicable to the local conditions and the data gathered. The components were carefully selected to satisfy the necessities of a reliable semi-manually operated fish scale remover.

The semi-manually operated fish scale remover has the following parts, to wit:

1) Support frame. This was fabricated using $1 \frac{1}{2} "{ }^{\prime \prime} \times 1 / 8 " \times 20 \mathrm{~cm}$ angle bars. With a height of about $85 \mathrm{~cm}$ from the ground, the support frame is $65 \mathrm{~cm}$ wide. It is in the form of pyramid frustum.

2) Scaling board. This is a rectangular shaped platform made from gauge \# 18 GI sheet. It has a thickness of $10 \mathrm{~cm}$, a length of $68 \mathrm{~cm}$ and a width of $40 \mathrm{~cm}$. A rectangular slit was cut from the scaling board 
wherein the fish scale remover is mounted. It has a $33 \mathrm{~cm}$ long opening at the right side of the scaling board for cleaning/removing the fish scales after each test.

3) Another part of the machine responsible in the scaling of the fish is the scaling drum. It is a pyramid frustum shaped good lumber with a diameter and a length of $12 \mathrm{~cm}$ and $30 \mathrm{~cm}$, respectively.

4) A 0.395-kiloWatt motor with a variable speed button at the left side underneath the scale hopper is connected to the shafting of the scaling drum and served as the prime mover. The rotational power is transmitted from the motor to the scaling drum through a V-belt and pulley system.

5) The hopper of the scale remover was constructed to gather the detached scales and is made from a 33 $\mathrm{cm} \times 60 \mathrm{~cm}$ gauge \#18 GI sheet.

\subsection{SELECTION, SPECIFICATION AND POSITIONING OF MATERIALS}

Having finished the fabrication of the different parts of the fish scale remover, the same are assembled into the manually operated fish scale remover shown below.

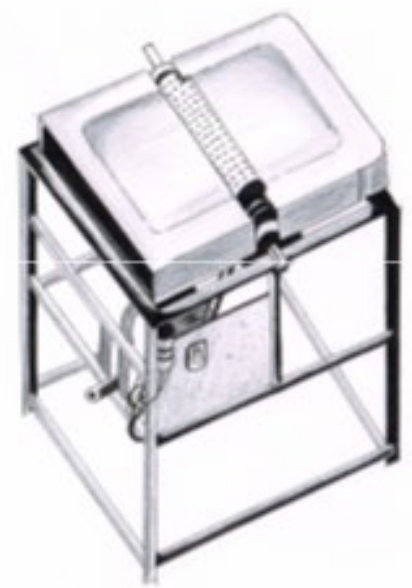

\subsection{COST ESTIMATION}

In this particular activity, the researchers estimated the total cost of the machine considering the prevailing prices of the materials and labor needed in the construction of the machine.

\subsection{TESTING PROCEDURE}

After the fabrication of the machine has been completed, a series of tests were conducted to determine its performance.

Three (3) different kinds of fish (bangus, sagision and kirawan) with three (3) different size of scales (large, medium and large) were used in the testing of the semi-manually operated fish scale remover at three (3) varying speeds of scaling drum (high, medium and low).

The following are the step by step procedure during the testing of the semi-manually operated fish scale remover:

1) The semi-manually operated fish scale remover was ran at low speed and, when the drum rotation is already stable, the sample fish (bangus) is immediately placed on top of the scaling drum one at a time until all the $1 \mathrm{~kg}$ bangus samples were scaled off.

2) When the samples were completely scaled, the machine was immediately shut off and the operating time was recorded.

3) The removed and unremoved scales (to be removed manually) were then noted and placed on the drying tray. 
4) The testing at medium and high drum speed were conducted following the testing at low speed drum rotation.

5) Steps 1 to 4 were repeated three (3) times, thus making a total of three replications for bangus.

6) After drying the removed and unremoved scales, they were weighed for the determination of the scaling efficiency.

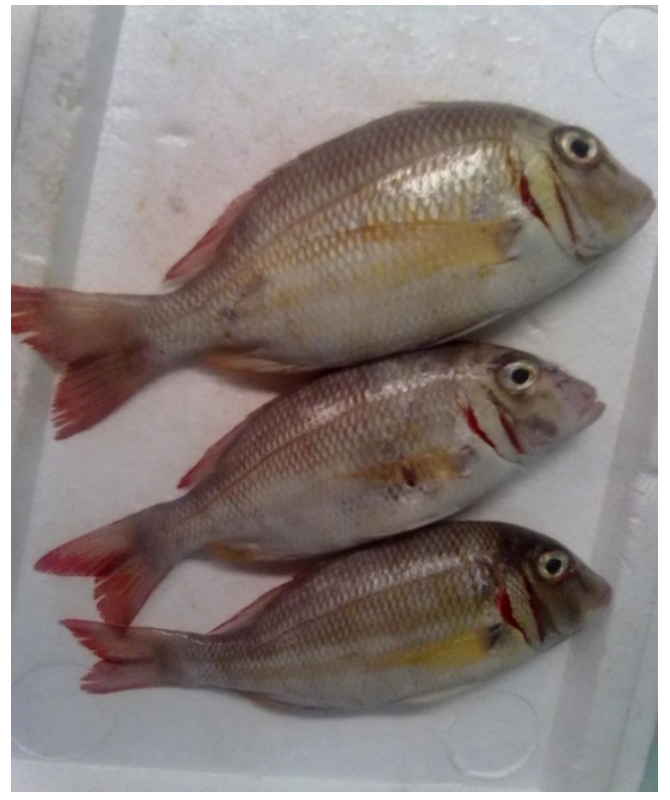

Kirawan

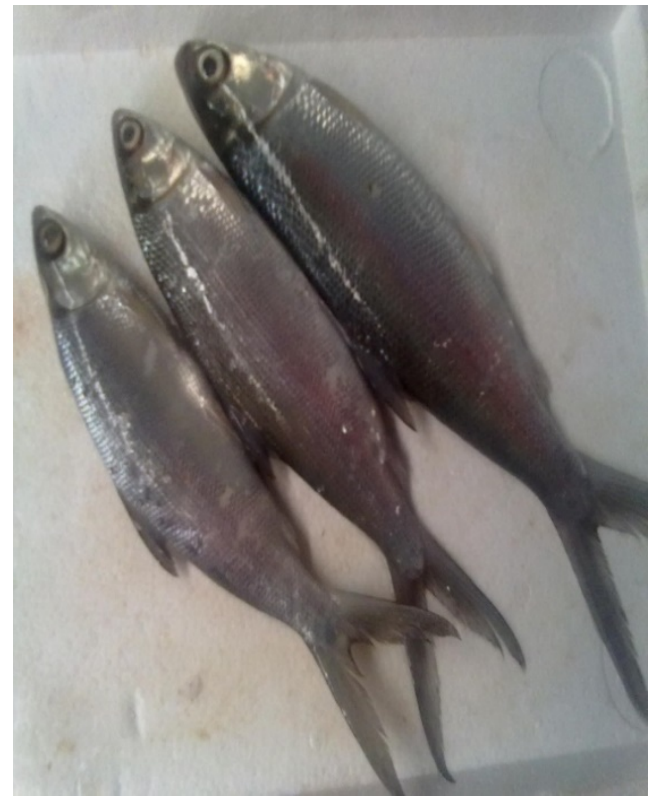

Bangus

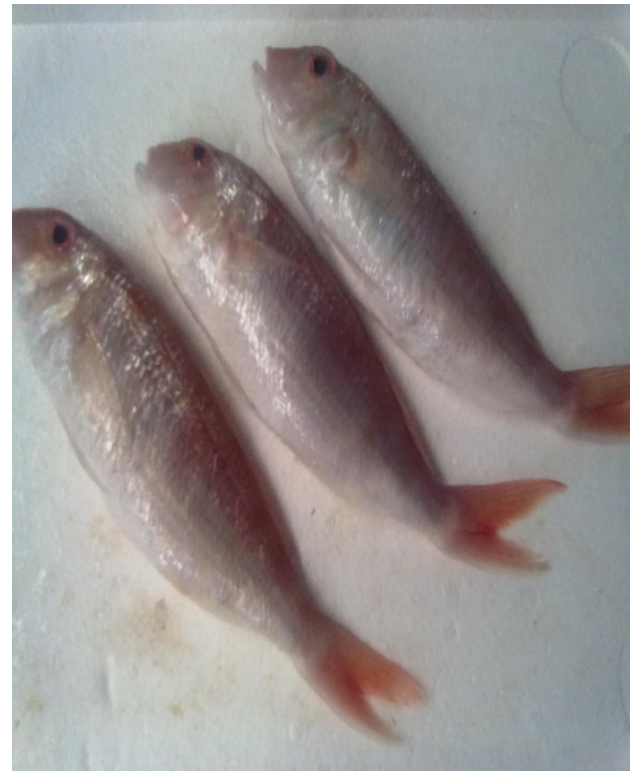

Sagision

7) The above steps for the testing of the fish scale remover using bangus fish were repeated for sagision and kirawan as samples.

8) After testing, the following were computed based on the data gathered:

- Scaling Capacity Scaling Capacity $=\frac{\text { Weight of Fish }(\mathrm{kg})}{\text { Operating Time }(\mathrm{hr})}$

- $\quad$ Scaling Efficiency

Scaling Efficiency $=\frac{\text { Weight of Removed Scales }(g)}{\text { Total Weight }(g)} \times 100$ 
Where:

Total Weight of Scales $=$ Removed Scales + Unremoved Scales

\subsection{COST AND RETURN ANALYSIS}

Using the given information and assumptions in the table below, a cost and return analysis was conducted to determine the desirability of the machine.

Table 2: Basic information and assumptions used in the cost and return analysis of the semi-manually operated fish scale remover

\begin{tabular}{|c|c|}
\hline ITEM & ASSUMPTION \\
\hline Initial cost of the Semi-Manually Operated Fish Scale Remover & 尹 $12,751.00$ \\
\hline Salvage Value of the Semi-Manually Operated Fish Scale Remover & $20 \%$ of IC \\
\hline Repair and Maintenance & $5 \%$ of IC \\
\hline Capacity of the Machine & g/day \\
\hline Useful Life of the Machine & ears \\
\hline Operating Days Per Year & ys $/$ year \\
\hline Labor Cost & $\mathrm{P} 150 / \mathrm{day}$ \\
\hline Price of Fresh Fish & $\mathrm{P} 180.00 / \mathrm{kg}$ \\
\hline Price of Descaled Fresh Fish & $\mathrm{P} 195.00 / \mathrm{kg}$ \\
\hline
\end{tabular}

The following formulas were used in the cost and benefit analysis, as follows:

\section{1) Fixed Cost per Year}

The fixed cost per year was computed using the depreciation (straight line method)

$\mathrm{D}=\frac{I C-S V}{n}$

Where:

$\mathrm{D}=$ Depreciation

IC = Initial cost of the machine

$\mathrm{SV}=$ Salvage Value of the machine

$\mathrm{N}=$ Life Span of the machine (yr)

\section{2) Variable Cost per Year}

Labor Cost $=$ Annual hours of utilization $\mathrm{x}$ hiring rate

\section{3) Total Operating Cost (TOC)}

$\mathrm{TOC}=\mathrm{FC}+\mathrm{VC}$

\section{4) Output Capacity (OC)}

OC = Mass of Sample Fish / Time to Finish Scaling

\section{5) Payback Period}

Payback period (years) $=\frac{\text { Investment }- \text { Salvage Value }}{\text { Net Annual Cash Flow }}$ 
Fabrication and Testing of a Semi-Manually Operated Fish Scale Remover

\section{6) Rate of Return}

$$
\mathrm{r}=\frac{\text { Net Annual Profit }}{\text { Capital Invested }}
$$

\section{RESULTS}

The researchers developed and constructed a semi-manually operated fish scale remover consisting of the following parts:

1) Machine Support Frame

2) Scaling Drum

3) Scaling Board / Platform

4) Scale Collecting Hopper

5) Motor

The component parts and the materials used in the fabrication of the above manually operated fish scale remover are the following:

Table 3: The component parts and materials used in the fabrication of the manually operated fish scale remover.

\begin{tabular}{|c|c|c|}
\hline Quantity & Unit & Description \\
\hline 1 & pc & Second-hand Aircon Motor with variable speed \\
\hline 2 & pcs & Pillow Block Bearing \\
\hline 1 & pc & Lauan wood $(12 \mathrm{~cm} \times 30 \mathrm{~cm})$ \\
\hline 1 & $\mathrm{~kg}$ & Concrete nails (1") \\
\hline 1 & pc & G.I Pipe $(3 / 4 " x 50 \mathrm{~cm})$, sched. 20 \\
\hline 1 & pc & Angle Bar $\left(1 \frac{1}{2} 2^{\prime \prime} \times 1 / 8 " \times 20 \mathrm{~cm}\right)$ \\
\hline 1 & pc & Stainless Solid Shafting (1" Ø x 24") \\
\hline 1 & sheet & Steel Plate (gauge \#18) \\
\hline 1 & pc & Single-grooved V-Pulley (3/4" Ø) \\
\hline 1 & pc & V-Belt(A-37) \\
\hline 4 & set & Bolt with nut $(1 / 2 \times 2 ")$ \\
\hline 12 & set & Bolt with nut $(1 / 2 \times 1 ")$ \\
\hline 6 & set & Bolt with nut $\left(1 \frac{1 / 2}{2}\right.$ X $\left.1 "\right)$ \\
\hline 12 & set & Bolt with nut ( $1 / 4 "$ x 1 ") \\
\hline
\end{tabular}

The actual cost of fabrication of the semi-manually operated fish scale remover was estimated using the prevailing prices of materials in the market as presented below.

Table 4: Cost of fabricating the semi-manually operated fish scaler.

\begin{tabular}{|c|c|c|c|}
\hline Quantity & Materials & Price per Unit & Amount \\
\hline $1 \mathrm{pc}$ & Second-hand Aircon Motor with Variable Speed & P $1,800.00$ & $\mathrm{P} 1,800.00$ \\
\hline 2 pcs & Pillow Block Bearing & 200.00 & 400.00 \\
\hline $1 \mathrm{pc}$ & Lawaan lumber $(12 \mathrm{~cm} \times 30 \mathrm{~cm})$ & 680.00 & 680.00 \\
\hline $1 / 2 \mathrm{~kg}$ & Concrete nails (1") & 180.00 & 90.00 \\
\hline $1 \mathrm{pc}$ & G.I. Pipe $(3 / 4 " x 50 \mathrm{~cm})$, sched. 20 & 350.00 & 350.00 \\
\hline $1 \mathrm{pc}$ & Angle Bar $\left(1 \frac{1}{2} "{ }^{\prime \prime} \times 1 / 8 " \times 20 \mathrm{~cm}\right)$ & 410.00 & 410.00 \\
\hline $1 \mathrm{pc}$ & Stainless Solid Shafting (1" Ø x 24") & 700.00 & 700.00 \\
\hline $1 \mathrm{sht}$ & Steel Plate (gauge \#18) & $1,100.00$ & 550.00 \\
\hline $1 \mathrm{pc}$ & Single-grooved V-Pulley $(3 / 4 " \varnothing)$ & 300.00 & 300.00 \\
\hline $1 \mathrm{pc}$ & Single-Grooved V-Pulley (1" Ø) & 450.00 & 450.00 \\
\hline $1 \mathrm{pc}$ & V-Belt (A-37) & 160.00 & 160.00 \\
\hline 4 sets & Bolt with nut $(1 / 2 \times 2 ")$ & 30.00 & 120.00 \\
\hline
\end{tabular}


Michael Dave B. Ablazo, Richelle O. Ampuan, Rommel P. Noble, and Benjamin D. Varela

\begin{tabular}{|c|c|c|c|}
\hline 12 sets & Bolt with nut (1/2 x 1") & 8.00 & 96.00 \\
\hline 6 sets & Bolt with nut (11/2" X 1") & 13.00 & 78.00 \\
\hline 12 sets & Bolt with nut (1/4" x 1") & 6.00 & 72.00 \\
\hline & \multicolumn{2}{|c|}{ Total Material Cost } & P $6,256.00$ \\
\hline & \multicolumn{2}{|c|}{ Add: Miscellaneous Expenses } & P $1,500.00$ \\
\hline & \multicolumn{2}{|c|}{ Add: Labor Cost } & 承 $5,000.00$ \\
\hline & \multicolumn{2}{|c|}{ GRAND TOTAL } & P $12,756.00$ \\
\hline
\end{tabular}

The performance testing of the semi-manually operated fish scale remover was conducted to determine the machine's scaling capacity and scaling efficiency.

Table 5 presents the scaling capacity of the machine using the three (3) different kinds of fish with different size of scales (large, medium, and small scales) when the scaling drum was run at varying speeds of the scaling drum (high, medium and low).

Table 5: The scaling capacity of the semi-manually operated fish scale remover.

\begin{tabular}{|c|c|c|c|c|c|c|}
\hline \multirow{2}{*}{$\begin{array}{c}\text { Kind of } \\
\text { Fish }\end{array}$} & \multirow{2}{*}{ Drum Speed } & \multicolumn{2}{|c|}{ Scaling Capacity $(\mathrm{kg} / \mathrm{hr})$} & \multirow{2}{*}{ Total } & \multirow{2}{*}{ Mean } \\
\cline { 2 - 7 } & & $\mathrm{R} 1$ & $\mathrm{R} 2$ & $\mathrm{R} 3$ & & \\
\hline \multirow{3}{*}{ Bangus } & $\mathrm{L}$ & 27.00 & 52.20 & 32.76 & 111.96 & 37.32 \\
\cline { 2 - 7 } & $\mathrm{M}$ & 46.44 & 60.84 & 90.00 & 197.28 & 65.76 \\
\cline { 2 - 7 } & $\mathrm{H}$ & 55.08 & 77.04 & 158.76 & 290.88 & 96.96 \\
\hline \multirow{3}{*}{ Sagision } & $\mathrm{L}$ & 87.84 & 32.76 & 34.56 & 155.16 & 51.72 \\
\cline { 2 - 7 } & $\mathrm{M}$ & 78.48 & 52.92 & 68.40 & 199.80 & 66.60 \\
\cline { 2 - 7 } & $\mathrm{H}$ & 118.44 & 83.16 & 102.96 & 304.56 & 101.52 \\
\hline \multirow{3}{*}{ Kirawan } & $\mathrm{L}$ & 52.20 & 60.12 & 69.12 & 181.44 & 60.48 \\
\cline { 2 - 7 } & $\mathrm{M}$ & 78.12 & 78.84 & 83.52 & 240.48 & 80.16 \\
\cline { 2 - 7 } & $\mathrm{H}$ & 100.08 & 135.00 & 141.84 & 376.92 & 125.64 \\
\hline
\end{tabular}

The results revealed that the highest scaling capacities of the machine were obtained for the descaling of Kirawan with $125.64,80.16$, and $60.48 \mathrm{~kg} / \mathrm{hr}$ when the scaling drum was set at high, medium, and low speeds, respectively. On the other hand, the lowest scaling capacities of the machine were recorded for the descaling of Bangus with 96.96, 65.76, and $37.32 \mathrm{~kg} / \mathrm{hr}$ when the scaling drum was set at high, medium, and low speeds, respectively. Generally, the results revealed that the highest and lowest speeds of the scaling drum resulted to the machine's highest and lowest scaling capacities, respectively, for the three (3) kinds of fish used in the testing.

Table 6 presents the scaling efficiency of the semi-manually operated fish scale remover. It shows that the highest and lowest average scaling efficiency of the machine were 82.21 and $73.25 \%$ when the scaling drum was set at medium and high speed, respectively, for bangus. For sagision, the highest and lowest average scaling efficiency of the machine were 74.52 and $69.71 \%$ when the scaling drum was set at low and high speed, respectively. Finally, the machine had highest and lowest average scaling efficiencies of 83.35 and $72.56 \%$ for kirawan when the scaling drum were set at medium and low speed, respectively.

Table 6: The scaling efficiency of the semi-manually operated fish scale remover.

\begin{tabular}{|c|c|c|c|c|c|c|}
\hline \multirow{2}{*}{$\begin{array}{c}\text { Kind of } \\
\text { Fish }\end{array}$} & Drum Speed & \multicolumn{2}{|c|}{ Scaling Efficiency (\%) } & Total & \multirow{2}{*}{ Mean } \\
\cline { 2 - 7 } & & R1 & R2 & R3 & & \\
\hline \multirow{3}{*}{ Bangus } & $\mathrm{L}$ & 76.00 & 75.30 & 68.45 & 219.75 & 73.25 \\
\cline { 2 - 7 } & $\mathrm{M}$ & 78.57 & 84.62 & 92.44 & 255.63 & 82.21 \\
\cline { 2 - 7 } & $\mathrm{H}$ & 72.73 & 77.78 & 90.00 & 240.51 & 80.17 \\
\hline \multirow{3}{*}{ Sagision } & $\mathrm{L}$ & 69.44 & 65.22 & 88.89 & 223.55 & 74.52 \\
\cline { 2 - 7 } & $\mathrm{M}$ & 81.82 & 67.86 & 62.50 & 212.18 & 70.73 \\
\cline { 2 - 7 } & $\mathrm{H}$ & 72.73 & 73.91 & 62.50 & 209.14 & 69.71 \\
\hline \multirow{3}{*}{ Kirawan } & $\mathrm{L}$ & 64.44 & 71.43 & 81.82 & 217.69 & 72.56 \\
\cline { 2 - 7 } & $\mathrm{M}$ & 71.64 & 90.90 & 87.50 & 250.04 & 83.35 \\
\cline { 2 - 6 } & $\mathrm{H}$ & 71.43 & 92.85 & 85.71 & 249.99 & 83.33 \\
\hline
\end{tabular}


Comparing the average scaling efficiencies across the different fish used in the test reveals that at low speed setting the scale removal of sagision and kirawan had the highest and lowest average scaling efficiencies of 74.52 and $72.56 \%$, respectively; at medium speed setting the scale removal of kirawan and sagision had the highest and lowest average scaling efficiencies of 83.35 and $70.73 \%$, respectively; and at high speed setting the scale removal of kirawan and sagision had the highest and lowest average scaling efficiencies of 83.33 and 69.71\%, respectively.

\section{DISCUSSION}

The Analysis of Variance showed that the mean scaling capacity significantly varied with respect to the scaling drum speed only. This means that the scaling capacity is affected only by the scaling drum speed such that "at high scaling drum speed, the scaling capacity is also high." The DMRT at 5\% level of significance revealed that, at high drum speed, the mean scaling capacity of machine for Sagision and Kirawan were significantly higher than that for Bangus. On the other hand, the mean scaling capacities of the machine at medium and low drum speeds were not significantly different for all of the three kinds of fish (Table 5). Practically, this means that, for the descaling of fish at a commercial scale, a high drum speed should be used.

Table 7: The mean scaling capacities of the machine at the different testing combinations.

\begin{tabular}{|c|c|c|}
\hline Fish & Drum Speed & Mean Scaling Capacity $(\mathrm{kg} / \mathrm{hr})$ \\
\hline Kirawan & High & $125.64^{\mathrm{a}}$ \\
\hline Sagision & High & $101.52^{\mathrm{a}}$ \\
\hline Bangus & High & $96.96^{\mathrm{ab}}$ \\
\hline Kirawan & Medium & $80.16^{\mathrm{bc}}$ \\
\hline Sagision & Medium & $66.60^{\mathrm{bcd}}$ \\
\hline Bangus & Medium & $65.76^{\mathrm{bcd}}$ \\
\hline Kirawan & Low & $60.48^{\mathrm{bcd}}$ \\
\hline Sagision & Low & $51.72^{\mathrm{cd}}$ \\
\hline Bangus & Low & $37.32^{\mathrm{d}}$ \\
\hline
\end{tabular}

Table 8 presents the mean scaling capacity using the semi-manually operated fish scale remover and the mean scaling capacity of an experienced fish vendor. The table shows that using the machine, $66.68 \mathrm{~kg} / \mathrm{hr}$ of bangus, $73.03 \mathrm{~kg} / \mathrm{hr}$ of sagision, and $88.80 \mathrm{~kg} / \mathrm{hr}$ were descaled. On the other hand, by manual scaling done by an experienced fish vendor, $83.10 \mathrm{~kg} / \mathrm{hr}$ of bangus, $64.62 \mathrm{~kg} / \mathrm{hr}$ of sagision, and $33.44 \mathrm{~kg} / \mathrm{hr}$ of kirawan were descaled. The data shows that the machine can descale fish with large scales faster than it can descale fish with small scales whereas the experienced fish vendor can descale fish with small scales faster than those with large scales.

Table 8: The comparison between the mean scaling capacity using the semi-manually operated fish scale remover and the mean scaling capacity of three experienced fish vendors.

\begin{tabular}{|c|c|c|}
\hline \multirow{2}{*}{ Fish } & \multicolumn{2}{|c|}{ Mean Scaling Capacity } \\
\cline { 2 - 3 } & Fish Scale Remover & Fish Vendor \\
\hline Bangus & 66.68 & 83.10 \\
\hline Sagision & 73.03 & 64.62 \\
\hline Kirawan & 88.80 & 33.44 \\
\hline
\end{tabular}

The analysis of variance revealed no significant differences in the average scaling efficiencies of the machine at the different drum scaling speeds and for the different fish.

Table 9 presents the result of the cost and return analysis for the fish scaler as follows:

Table 9: Cost and return analysis of the fish scale remover.

\begin{tabular}{|c|cc|}
\hline Details & \multicolumn{2}{|c|}{ Computed Value } \\
\hline Initial Cost of Fish Scale Remover & P & $12,756.00$ \\
\hline Depreciation Cost / year & P & $1,020.00$ \\
\hline
\end{tabular}


Michael Dave B. Ablazo, Richelle O. Ampuan, Rommel P. Noble, and Benjamin D. Varela

\begin{tabular}{|c|cc|}
\hline Repairs and Maintenance Cost / year & P & 637.55 \\
\hline Labor Cost / year & P & 3,600 \\
\hline Fish / year & P & $648,000.00$ \\
\hline Total Operating Cost per year & P & $653,275.53$ \\
\hline Annual Gross Income & P & $702,000.00$ \\
\hline Annual Net Income & P & $48,724.37$ \\
\hline Payback Period & \multicolumn{2}{|c|}{50 days } \\
\hline Rate of Return & \multicolumn{2}{|c|}{3.82} \\
\hline
\end{tabular}

The researchers concluded that the semi-manually operated fish scale remover should, at least, consist of a machine support frame, scaling drum, scaling board / platform, scale collecting hopper, and a motor as prime mover with an actual cost of onstruction of $\mathbf{P} \mathbf{1 2 , 7 5 6 . 0 0}$. The study has proven that the higher the speed of the scaling drum, the higher is the scaling capacity of the manually-operated fish scale remover and that the bigger the scales of fish being descaled, the higher is the scaling capacity of the manually-operated fish scale remover.

On the scaling capacity of the fish scale remover, this has higher average scaling capacity than the average scaling capacity of experienced fish vendors for kirawan and sagision but is lower than that of the experienced fish vendors for bangus.

On the scaling efficiency, the fish remover's efficiency for all the fish used in testing the it were highest at medium speed setting of the scaling drum.

Finally, the cost and return analysis on the operation of the semi-manually operated fish scale remover revealed that it will have an annual net income of $\mathrm{P} 48,724.37$, a payback period of 50 days, and a rate of return of 3.82.

The researchers would like to recommend that in the conduct of testing for the manually-operated fish scale remover, the bigger sized fish (about 3- 5 kilograms) should be included; two or three differently designed scaling drums may be tested; and that the optimum scaling drum speed that will result to the highest scaling efficiency without destroying the fish skin be determined.

\section{SOURCES OF FUNDING}

This research received no specific grant from any funding agency in the public, commercial, or not-for-profit sectors.

\section{CONFLICT OF INTEREST}

The author have declared that no competing interests exist.

\section{ACKNOWLEDGMENT}

None.

\section{REFERENCES}

[1] DELA CRUZ, C.R. 1983. A Technical Manual for Small and Medium Scale Coastal Fish Farms in Southeast Asia. Manila, Philippines.

[2] BYRD, A. 1951. Research Report for Fishery Technology. Retrieved August 16, 2013.

[3] CLUCAS, I.J. and SUTLIFFI, P.J. 1981. An Introduction to Fish Handling and Processing.

[4] TRIPODI, H., SAGERS, F. W. AND PLOY, A. 1974. Fish Scaler. Serial No. 451 \& 521. Retrieved September 14, 2013. 